The international development of the 'Social Norms' approach to drug education and prevention

Dr John McAlaney*

Lecturer in Psychology

Centre for Psychology Studies

Richmond Building

University of Bradford

Bradford, BD7 1DP

United Kingdom

Bridgette Bewick

Lecturer

Leeds Institute of Health Sciences

Faculty of Medicine and Health

Worsley Building

University of Leeds

Leeds, LS2 9JT

United Kingdom

Dr Clarissa Hughes

Research Fellow

Department of Rural Health

Anne O’Byrne Centre

Locked Bag 1372

Launceston 7250

University of Tasmania

Tasmania, Australia

* Lead author and address for correspondence

Email - j.mcalaney@bradford.ac.uk

Tel - (+44)1273 236775

Fax - (+44)1273 235295

Keywords - social norms, alcohol, binge, drug education 


\title{
The international development of the 'Social Norms' approach to drug education and prevention
}

\begin{abstract}
The social norms approach to health promotion has become remarkably popular in the last 20 years, particularly in the American college system. It is an alternative to traditional fear based approaches of health education, which a growing body of research demonstrates is often ineffective in reducing alcohol and drug misuse. The social norms approach differs by recognising that individuals, particularly young adults, tend to overestimate how heavily and frequently their peers consume alcohol, and that these perceptions lead them to drink more heavily themselves than they would otherwise do. Similar misperceptions have been found in a range of other health and non-health behaviours. The social norms approach aims to reduce these misperceptions, and thus personal consumption, through the use of media campaigns and personal feedback. Although the numbers of completed social norms projects outside the USA is small the evidence from them is that the approach can be equally effective in both European and Australian contexts. It is also acknowledged that as an emergent field there are limitations to the current social norms literature. There is a lack of randomised control trial studies, a lack of clarity of the role of referent groups and a need to better understand the processes through which misperceptions are transmitted. However despite these issues the social norms approach represents a new avenue for reducing alcohol and drug related harm and is an area which merits further research.
\end{abstract}




\section{The international development of the 'Social Norms' approach to drug education and prevention}

\section{Introduction}

The 'social norms' approach to health promotion has experienced a rapid and impressive rise to prominence. In the space of only two decades it has become one of the most widely used prevention approaches in the United States, particularly within the education sector, and use of the approach is steadily gaining momentum in the UK, Canada and other countries. By 2001, almost half of US four-year colleges surveyed reported having conducted a social norms marketing campaign (Wechsler 2004). Borsari and Carey (2003) have noted the 'veritable explosion' of social norms campaigns in recent years. Researchers, evaluators and prevention professionals in the ATOD field are not the only people paying attention to the theoretical insights and practical applications of social norms in the effort to reduce drug-related harm. The broad popular appeal of the approach was captured by its naming as New York Times Magazine's 'Idea of the Year' in 2001 (Frauenfelder 2001).

The growth of the social norms approach is perhaps partially explained by growing disenchantment with conventional prevention approaches. Since the 1980s, in particular, conventional forms of alcohol and drug health education have been increasingly viewed as ineffectual, in light of reviews of the research evidence (e.g. Foxcroft et al. 2003). Many conventional approaches are based upon (questionable) assumptions concerning the target groups' lack of knowledge concerning the risks associated with the use of alcohol and other drugs, and frequently utilise 'fear appeals'. Such appeals, which are also known as 'scare tactics' or 'health terrorism', typically emphasise the negative outcomes of behaviours. Unfortunately, such risk-focused campaigns may be dismissed by the target population since they believe - often correctly - that the type of extreme negative outcome depicted is in fact unlikely to occur.

Unlike interventions designed to frighten or confront target groups, social norms projects focus on the perceptions that people have of the behaviour and attitudes of those around them, and the influence that those perceptions have on their own behaviour and attitudes. As will be explained later in this article, it is the areas of 'misperception' which are of particular concern within a social norms framework. 'Environments of perceptual distortion' i.e. where risky behaviours such as 'binge drinking' are perceived to be more prevalent or more widely accepted than they really are, can themselves make substance use more likely. Thus, social norms projects commonly seek to bring behavioural and/or attitudinal perceptions into alignment with the 'actual' peer use and attitudes

Many social norms projects, particularly those on college campuses, contain a significant 'social marketing' component. In other words, they seek to prompt behaviour change by 'selling' ideas and attitudes, based on 
the marketing experience of selling physical products in the business world. Although the two approaches are highly compatible, they are not synonymous. We argue that the distinction between them should be retained. If social norms approaches are the product, then social marketing is the packaging through which that product is sold and delivered.

Another explanation for the growing popularity of the social norms approach is its versatility. Although many early social norms projects were conducted with university students, the approach has also been successfully applied to both younger and older target groups. Similarly, following on from the successful use of the approach in the alcohol and drug field, the social norms approach has now also been applied to a diverse array of behaviours including sunscreen use (Mahler et al. 2008), rumor spreading in high school (Cross and Peisner 2009) and towel re-use in hotels (Goldstein et al. 2008).

This article traces the development of the social norms approach as an innovative, theoretically-informed model for the prevention of drug-related harm. After briefly discussing the early theoretical foundations of the approach, it presents examples of how the model has been applied in the ATOD field within educational and other settings in the United States. It then considers the wider influence of the work in the USA, noting its more recent application in the United Kingdom and Australia and outlining the key benefits of cross-cultural work. Finally, it considers some of the main criticisms that have been levelled at social norms theory and/or practice, as a basis for suggesting ways in which the conceptual development of the approach, as well as its practical application, might be enhanced.

\section{Conceptual foundations of the social norms approach}

The social norms approach currently employed in the USA is often cited as having originated from a study by Perkins and Berkowitz (1986), in which it was noted that students at Hobart and William Smith Colleges in New York tended to overestimate how heavily and how frequently their peers drank alcohol. Similar misperceptions were later identified at over one hundred American college campuses by secondary analysis of two national surveys; the Core Alcohol and Drug Survey (Perkins et al. 1999) and the National College Health Assessment (Perkins et al. 2005). In addition to misperceptions about rates of behaviours (descriptive norms) research studies have also revealed misperceptions about the perceived acceptability of behaviour (injunctive norms). For example, students commonly overestimate how permissive their peers are towards heavy drinking (Prentice and Miller 1993).

The existence of misperception is a matter of concern, as there is an ample evidence base that perceived norms of others consistently predict how heavily an individual drinks (Perkins and Wechsler 1996; Clapp and McDonnell 2000). As individuals, we are strongly influenced by what we perceive to be the group norms of our peers. This phenomenon has been 
studied in psychology for many years following from the work of researchers such as Asch (1951). These and related studies have also demonstrated that normative misperceptions occur with regards to other substance misuse behaviours, including drug use and smoking (Wolfson 2000; Haines et al. 2003). Further studies have also discovered normative misperceptions in other health behaviours such as gambling (Neighbors et al. 2007) and sexual behaviours (Lewis et al. 2007) .

\section{The Social Norms approach to prevention}

Research into normative misperceptions has given rise to a new form of alcohol and drug intervention, known primarily as the social norms approach. This premise of this approach is simple; if individuals' misperceptions can be corrected then the social pressure on them to engage in alcohol/ drug use will be lessened and their own use will fall. In parallel with research on misperceptions the development of social norms campaigns has largely occurred in the substance misuse field and targeted college students, although it is increasingly being applied to other domains and populations.

Misrepresentation of the alcohol and drug use rates of a group can be harmful as it can lead to increased personal use than would otherwise be the case. This is particularly relevant to college and university students, where transition into adulthood often coincides with a move to a new environment where new peer networks must be formed (Roche and Watt 1999). A student's peers at a college or university often serve as their most salient social referent (Perkins 1997) and as such it is important that students do not have exaggerated views of peer drinking behaviour (for a review of social influences on college students see Bosari and Carey 2001.

To date, most social norms work has been focussed on student populations, although as shall be discussed the field is rapidly expanding into other groups. In doing so, it has challenged a dominant stereotypical view of young people by demonstrating that the majority of them do not drink alcohol heavily and frequently and do not abuse drugs. This should not be interpreted as trivialising or denying the existence of alcohol misuse among young people. Studies from the USA and the UK clearly demonstrate that alcohol misuse is a particular problem in student populations (Gill 2002; White et al. 2006), with numerous negative consequences for both the student and those around them (Perkins 2002). However social norms research does stress that figures of alcohol and drug use must be kept in perspective. It is worth noting that even among young men (i.e. the heaviest drinking group) in the UK, frequent binge drinking is not the majority behaviour (McAlaney and McMahon 2006).

Many early social norms interventions utilised a global social norms campaign, which operates through posters, leaflets, radio adverts and other mass media channels. The goal of such campaigns is to disseminate the accurate drinking norms to the target population, such as 'Most (73\%) students at [college name] have no more than 4 alcoholic drinks on a night 
out'. This was first implemented in 1989 at Northern Illinois University, which reported a drop in rates of heavy drinking from $43 \%$ to $25 \%$ over a nine year period, accompanied by a reduction in the misperception of heavy drinking in peers from 70\% to 33\% (Haines and Barker 2003). Similar effects of social norms approaches have been documented at a number of additional American colleges including Hobart and William Smith Colleges (Perkins and Craig 2003) and the University of Arizona (Johannessen and Gilder 2003). The approach has been used extensively and successfully at the University of Virginia (Turner et al. 2008), which is also home to the National Social Norms Institute (www.nsni.org).

Relative to campaigns based on descriptive norms there is a lack of work addressing on injunctive norms. Barnett et al. (1996) were successful in reducing perceptions of approval of heavy drinking in both regular students and Greek fraternity members, although Schroeder and Prentice (1998) did not find similar changes at a longer term follow-up of 4 to 6 months. A recently published Cochrane Review concluded that there was evidence that the social norms approach could be used to reduce alcohol misuse, although as shall be discussed it also identified some weaknesses in the literature (Moreira et al. 2009).

There has been less social norms work in community settings in the USA, although the approach is becoming more widely used. One of the earliest and most developed examples of this is the MOST of Us project (www.mostofus.org which originated in Montana (Linkenbach 2003). This was done through the application of a seven step model based on planning a rigorous research design, collecting baseline data, developing and marketing social norms messages and then piloting, implementing and evaluating the campaign. Linkenbach (2003) note some of the challenges in conducting community-based work, such as the fact that there is often a lack of suitable data to use in a social norms campaign. This often necessitates the collection of baseline data, which in a community setting can be a difficult task.

The implementation of a social norms campaign can be more difficult in a community than in the traditional setting of a self-contained and relatively easily controlled environment of a college campus. It is of even greater importance that norms messages are consistently applied and spread through as many mediums as possible. Care must also be taken that there are not competing campaigns operating in the same environment. For example, a community social norms campaign to reduce heavy drinking in young adults could be very quickly undermined by a local school alcohol education programme based on conventional approaches based on fear appeals. Overall it could argued that when working outside the college campus social marketing techniques are particularly useful, as shall be discussed later. 
To date, the vast majority of social norms research has occurred within the USA and particularly the American college system, with similar work also being conducted in Canada (Perkins 2007b; Schmidt et al. 2009). Outside of the USA, misperceptions of peer alcohol use have also been documented in Scotland (McAlaney and McMahon 2007), England (Bewick et al. 2008), Hungary, Slovakia, Romania and the Czech Republic (Page et al. 2008). Several studies have found further evidence for misperceptions in Australian school children (Hughes et al. 2008a) and Finnish adolescents (Lintonen and Konu 2004). The approach has become widely used in Denmark, following the work conducted in projects such as the Ringsted Experiment. To date this work has not been publicised extensively in English language journals, however information about this and other Danish work is available on the website of the Danish Center for the Social Norms Approach (www.socialpejling.dk).

The degree of misperception found in these different populations internationally appears to be comparable to American studies. For example, in their study of Scottish students McAlaney and McMahon (2007) found that $52 \%$ of the sample reported that they believed the typical student on campus drank enough alcohol to be drunk twice a week whereas only $12 \%$ reported doing so. This is similar to the misperceptions found at analogous American colleges (e.g. Thombs et al. 2005), which is of interest given the legal and cultural differences between the two countries (Delk and Meilman 1996).

The social norms approach has also received attention outside the academic field internationally and is beginning to attract interest from policymakers in various countries. Following a presentation by Wesley Perkins at Scotland's Future Forum (Perkins 2007a) the potential of the social norms approach was discussed by the UK media (Naysmith 2007) and a motion was lodged in the Scottish Parliament by Bill Wilson MSP calling for the use of social norms approaches in Scotland (Wilson 2007). The use of the social norms approach was further discussed at a Social Norms Forum which was held in Brussels in 2009 and attended by the EU Director General for Health and Consumer Protection (www.socialnormsforum.eu).

Studies which have implemented the social norms approach outside of the American educational system are more limited in number, although there have been several projects in Europe and Australia, in addition to the aforementioned work in Denmark. Bewick, Trusler et al. (2008) at the University of Leeds have for example examined the use of web delivered personal feedback through the ongoing Unitcheck project (www.unitcheck.co.uk). The use of personalised, online feedback which emphasises risk reduction rather than abstinence has becoming widely used in the USA and appears to be particularly effective with high risk drinkers (e.g. Neighbors et al. 2004). In the work of Bewick, Trusler et al. (2008) and others (e.g. Lewis and Neighbors 2006) the technique has been combined with the social norms approach, where individuals receive 
online feedback on how their own drinking behaviour and their misperceptions of peer norms relate to actual norms .

The Unitcheck study also addressed an identified weakness in the literature Moreira, Smith et al. 2009in that it involved a randomised controlled trial (RCT). Students in the intervention group were presented with feedback which included health advice, personalised feedback on consumption and sensible levels of drinking, as well as social norms information on how personal consumption compared to peers. At 12 week follow- up the intervention group had a significantly greater reduction in alcoholic units consumed per drinking occasion than the control group, but no reduction in alcoholic units consumed per week. As such the study demonstrated the potential of personalised feedback containing social norms information in tackling heavy episodic, or binge, drinking. In doing so it also highlighted that the approaches used in the USA appear to be equally applicable to the UK, suggesting that the efficacy of social norms approaches are not a phenomenon which are culturally specific to the USA.

The Social Norms Analysis Project (SNAP) was the first major social norms study in Australia (Hughes et al. 2008b; Hughes, Julian et al. 2008a). As the authors note, Australia is similar to many countries worldwide in having actively provided alcohol education to adolescents for many years, particularly approaches based on educating them about the risks of consumption and encouraging them to resist peer group pressure to drink. They also highlight a lack of research evidence to support the effectiveness of such conventional approaches. SNAP was conducted at schools in rural areas of Tasmania (an island south of the Australian mainland). Following the social norms model developed in the USA, SNAP involved the collection and analysis of anonymous self-report data. Areas of misperceptions were identified and formed the basis for schoolspecific social norms messages. These messages focussed on stating the positive behaviour of the majority and avoided any negative content or scare tactics.

In contrast to many of the existing social norms studies in the USA, both the Bewick, Trusler et al. (2008) and Hughes, Julian et al. 2008a studies benefited from the inclusion of control groups. In the latter project, there was a significant reduction in the self-reported frequency of drunkenness in the intervention group compared to the control. No such reduction occurred with the frequency of drinking. Change was more evident in perceptions, with significant reductions in misperception of perceived frequency of both drinking and drunkenness. Overall therefore both this project and the Unitcheck project did not bring about large changes in behaviour. However it is important to state that it would have surprising if they had done so within the time frames when compared to the existing American literature. The numerous examples from the US college system demonstrate that behaviour change must first be pre-dated by perception change, as witnessed in both the UK and Australian projects, and that mass behaviour change will only occur after several years of sustained social norms campaigning. 


\section{Cross-cultural comparisons}

There are a number of similarities between Unitcheck and SNAP and other international work in the field. Hughes, Julian et al. (2008b) noted that perceptions of drunkenness appeared to be particularly influential on school pupil behaviour. This reflects the study by McAlaney and McMahon (2007), who found that a similar results with regards to Scottish university students. In the same study it was also noted that unlike misperceptions of other alcohol behaviours misperceptions about frequency of drunkenness in same age-peers did not appear to diminish with age. Frequency of drunkenness may therefore be a behaviour which is particularly vulnerable to misperception and one which is especially influential. This is feasible when considering the theories of the aetiology of normative misperceptions. Suggested causes of normative misperceptions stem from various social psychological constructs , as discussed by (Perkins 1997), which include pluralistic ignorance and attribution theory. Pluralistic ignorance refers to the when individual presume their own attitudes and behaviour to be more conservative than that of their peers, even when they are in fact identical (Schroeder and Prentice 1998). This has several consequences; firstly individuals misperceive the behaviour of the referent group and secondly perceive themselves to be deviant from the norm.

Attribution theory, as first discussed by Heider in 1958, also contributes to this overall misperception. It states that individuals have limited knowledge about how their peers actually feel and behave. If one student witnesses another drinking excessively for example then they will tend to assume that heavy drinking is the typical behaviour for that individual. Therefore upon witnessing someone drinking alcohol we will assume that drinking alcohol is a typical behaviour. Out of all the consumption behaviours, drunkenness is arguably easily the most noticeable and memorable; we are more likely to be immediately aware that those around us are drunk than we are to be aware of how many alcoholic drinks each individual in a group has had. Furthermore as Lintonen and Konu (2004) observe, drunkenness is the aspect of underage drinking which is usually the subject of media attention. It is worth noting that the media attention on heavy drinking could itself inadvertently fuel the behaviour it is often condemning by suggesting heavy drinking to be a more common than is the case (Perkins 2003). This is a matter of concern , since media focus on heavy drinking could be argued to be increasing, with the UK and other nations witnessing a growing number of typically alarmist news stories on alcohol misuse (Plant and Plant 2006).

Comparison of international studies also provides further support for the work in the USA regarding the role of the reference group and degree of misperception. Studies in Australia (Hughes, Julian et al. 2008a), the UK (McAlaney and McMahon 2007) and New Zealand (Kypri and Langley 2003) also surveyed young adults on normative perceptions in different reference groups. It has been theorised that the less contact an individual 
has with a referent group the greater the scope for misperception, as the individual has to generalise from fewer direct observations (Perkins 1997). In contrast, perceptions about close friends would therefore be expected to be more accurate, as the individual would have more direct observations of behaviour with which to refine their perceptions (Thombs et al. 1997).

Differences between countries have been noted when looking at gender effects. Research in the US college system has tended to find that woman have larger misperceptions about alcohol than men. Research in the UK (McAlaney and McMahon 2007) and Eastern Europe (Page, Ihasz et al. 2008) however has failed to find any comparable gender effect. For example, Lewis and Neighbors (2006) note that the choice of reference group in social norms study designs could have implications for how effective social norms campaigns are. Importantly, past studies tended to present normative information about the 'typical' student as part of the social norm campaign without establishing precisely who respondents perceived the 'typical student' to be. If the respondent perceives themselves to be dissimilar to the 'typical student' (e.g., in terms of ethnicity, gender, class, or age), according to social norm theory, the impact of the social norm should be lower, thereby reducing the effectiveness of the social norm campaign. There is some evidence to support this hypothesis. For example, Prentice and Miller (1993) found that whilst a social norms campaign prompted a change in normative beliefs and consumption in male students, which was maintained at eight week follow-up, there was no corresponding change in female students' normative beliefs and consumption. It could be that both male and female students perceived the 'typical' student to be male, which resulted in the campaign having less salience to female students (Lewis \& Neighbors, 2006). To test this hypothesis, Lewis and Neighbors (2006) conducted a normative belief survey in which they asked respondents to describe who they envisaged typical student at their college to be. Almost $94 \%$ of male students did indeed perceive the typical student to be male, whereas only half of the female sample perceived the typical student to be female.

\section{Criticisms of the social norms approach}

There have been several criticisms made of the social norms field and the associated interventions. A study which failed to find an underlying misperception was that by Wechsler and Kuo (2000). However this study was later criticised for using measures of perceived peer behaviour which were fundamentally different from the measure of personal behaviour (DeJong 2000). Similarly there have been studies which have failed to find the intervention is effective. Wechsler et al. (2003) conducted a study of social norms interventions implemented at colleges in the USA and concluded that there was little evidence that such interventions reduced alcohol misuse. These claims were later refuted by Perkins, Haines et al. (2005) who argued that the study failed to properly establish whether a social norms intervention had been conducted at the college. Studies have also been reported where social norms interventions were unsuccessful, however most of these were not successful in changing perceptions 
(Thombs et al. 2004). Social norms interventions must be implemented correctly. Simplistic media campaigns which are unclear or lack credibility can undermine the effectiveness of the approach (Granfield 2002; Thombs, Dottere et al. 2004).

In addition to these debates there are methodological issues in the field. One particular criticism which has been made with regards to the existing literature base is the lack of longitudinal studies of social norms interventions. This has in part been remedied by Neighbors et al. (2006) who examined the temporal precedence of perceived norms and behaviour. Whilst a degree of reciprocal causality was identified there was evidence that perceived norms were a stronger predictor of behaviour than behaviour was of perceived norms. Social norms studies are also often based on self-report, which has been criticised. However there have been a number of studies which have used breathalysers (e.g. Foss et al. 2003). Studies have also been criticised on measurement issues (Campo et al. 2003). Previous social norms campaigns have often included additional components (Borsari and Carey 2000; Walters 2000). Bosari and Carey (2001) observed that numerous different referent groups have been used in social norms studies. Prentice and Miller 1993 noted an order effect on perceived norms. As Bosari and Carey 2001 note there remains a lack of understanding over the exact mechanism by which social norms campaigns operate.

\section{Future directions}

Whilst the social norms approach has become widely used, there remain many unanswered questions and gaps in the underlying evidence base. One particular area of importance for social norms research is a better understanding of group identity and how individuals identify salient peers. The focus in past research has been on how reference groups influence the perceived norms; however it is also possible that the perceived norm influences group selection. As Borsari and Carey (1999) note students may self-select into a friendship network with comparable drinking levels to themselves. The process of choosing and cementing social networks, and the way in which they influence ones perceptions and behaviour is not well understood. Given that many students, upon arriving at university, are in the midst of developing new social networks college and university settings provide an opportune environment in which to further this understanding.

While research has tended to provide friends or students at the same college as a referent group little is understood about how individuals visualise these groups. For example when they are asked to report on the percentage of their friends who engage in drunken behaviour how do participants decide which of their friendship groups to draw from? Do they unconsciously choose friends of a particular gender, age, ethnicity or religion? As discussed there is some evidence that gender does play a role in what students see as a 'typical' student and suggests that there is a need for further work exploring this issue. It is also important that work is 
undertaken so salient reference groups can be accurately identified and targeted. As has been demonstrated in the aforementioned literature friends can be the strongest reference group in determining individual behaviour, however misperceptions about friends may be relatively minor and unsuitable for a social norms campaign. Misperceptions of other students may be greater, but the influence of this group on the individual may be weaker. The interplay between saliency, misperception and behaviour is an area which warrants further investigation.

There are numerous other areas into which the social norms field can expand. With the advent of new technologies it must for example be considered how the dissemination of norm messages can be improved. These technologies certainly play an important part in the drinking behaviour of young adults. As Moore and Miles (2004) note young adults frequently use online chat rooms, instant messaging and mobile phones to make decisions about their alcohol consumption behaviour. These new mediums of communication may provide alternative ways of conducting social norms campaigns, possibly by using the emergent field of social media marketing which utilises popular websites such as Facebook, YouTube and Twitter. To further understand how young adults do conceptualise their peers and form the social networks that transmit perceived it is perhaps also necessary to conduct more qualitative research. Previous research has relied largely on quantitative studies, often with a goal of confirming the existence of misperceptions or changes in behaviour following a social norms campaign. It could be argued though that there an ample evidence base supporting the existence of misperceptions and that future research studies should begin to study social norms in richer, more detailed and context specific ways.

In conclusion, the social norms approach has become widely used in the USA and it appears to be on a similar track in Europe and Australia. There are undeniable gaps in the literature and it could certainly be argued that at times the use of the social norms approach exceeds the evidence base. However these are issues which can only be addressed by continued research; and in particular work which expands the field beyond the American college system and into both community settings and different cultures. The social norms approach represents a fundamentally different way of tackling alcohol and drug misuse; it is an inclusive approach which is based on the positive rather than the negative. In the continued absence of evidence supporting traditional approaches to reducing alcohol and drug misuse the social norms approach is an avenue which should be pursued. 
References

Asch, S. E. (1951). Effects of group pressure upon the modification and distortion of judgment. Groups, Leadership, and Men: Research in Human Relations. H. Gueztkow. Oxford, Carnegie Press: 177 190.

Barnett, L., et al. (1996). Changing perceptions of peer norms as a drinking reduction program for college students. Journal of Alcohol and Drug Education, 39 - 62.

Bewick, B. M., et al. (2008). The feasibility and effectiveness of a webbased personalised feedback and social norms alcohol intervention in UK university students: A randomised control trial. Addictive Behaviors, 331192 - 1198.

Borsari, B. and Carey, K. (1999). Understanding fraternity drinking: five recurring themes in the literature, 1980 - 1998. Journal of American College Health, 4830 - 37.

Borsari, B. and Carey, K. (2000). Effects of a brief motivational intervention with college student drinkers. Journal of Consulting and Clinical Psychology, 68 728-733.

Bosari, B. and Carey, K. B. (2001). Peer influences of college drinking: A review of the research. Journal of Substance Abuse, 13391 - 424.

Bosari, B. and Carey, K. B. (2003). Descriptive and injunctive norms in college drinking: A meta - analytical integration. Journal of Studies on Alcohol, 64331 - 341.

Campo, S., et al. (2003). Are social norms campaigns really magic bullets? Assessing the effects of students' misperceptions on drinking behavior. Health Communication, 15(4) 481 - 497.

Clapp, J. D. and McDonnell, A. L. (2000). The relationship of perceptions of alcohol promotion and peer drinking norms to alcohol problems reported by college students. Journal of College Student Development, 41(1) 20 - 26.

Cross, J. E. and Peisner, W. (2009). RECOGNIZE: A social norms campaign to reduce rumor spreading in a junior high school. Professional School Counseling, 12(5) 365.

DeJong, W. (2000). Note to the field: the case of the missing misperception. Higher Education for Alcohol or Drug Prevention News Digest, 155.

Delk, E. and Meilman, P. W. (1996). Alcohol use among college students in Scotland compared with norms from the United States. Journal of American College Health, 44(6) 274 - 282.

Foss, R., et al. (2003). Enhancing a norms programme to reduce high risk drinking among first year students, University of North Carolina Chapel Hill.

Foxcroft, D., et al. (2003). Longer-term primary prevention for alcohol misuse in young people: A systematic review. Addiction, 98397 411.

Frauenfelder, M. (2001). Social norms marketing. New York Times Magazine. New York: 100. 
Gill, J. S. (2002). Reported levels of alcohol consumption and binge drinking within the UK undergraduate student population over the last 25 years. Alcohol \& Alcoholism, 37(2) 109 - 120.

Goldstein, N. J., et al. (2008). A room with a viewpoint: Using social norms to motivate environmental conservation in hotels. Journal of Consumer Research, 35(3) 472 - 482.

Granfield, R. (2002). Can you believe it? Assessing the credibility of a social norms campaign. Social Norms, 2(1 - 8).

Haines, M., et al., Eds. (2003). Using social norms to reduce alcohol and tobacco use in two midwestern high schools. The Social Norms Approach To Preventing School And College Age Substance Abuse: A Handbook For Educators, Counselors, And Clinicians. San Francisco, Jossey-Bass.

Haines, M. P. and Barker, G. P. (2003). The Northern Illinois University experiment: A longitudinal case study of the social norms approach. The Social Norms Approach to Preventing School and College Age Substance Abuse: A Handbook for Educators, Counselors and Clinicians. H. W. Perkins. San Francisco, JosseyBass: 21 - 34.

Heider, F. (1958). The Psychology of Interpersonal Relations. New York, John Wiley \& Sons.

Hughes, C., et al. (2008a). Harnessing the Power of Perception: Reducing Alcohol-Related Harm among Rural Teenagers. Youth Studies Australia, 27(2) 26 - 36.

Hughes, C., et al. (2008b). Trialling 'Social Norms' Strategies for Minimising Alcohol-Related Harm Among Rural Youth (Social Norms Analysis Project): Final Evaluation Report to the Alcohol Education and Rehabilitation Foundation. Hobart.

Johannessen, K. and Gilder, P. (2003). The University of Arizona's campus health social norms media campaign. The Social Norms Approach to Preventing School and College Age Substance Abuse: A Handbook for Educators, Counselors and Clinicians. H. W. Perkins. San Francisco, Jossey-Bass.

Kypri, K. and Langley, J. D. (2003). Perceived social norms and their relation to university student drinking. Journal of Studies on Alcohol, 64(6) 829-34.

Lewis, M. A. and Neighbors, C. (2006). Social norms approaches using descriptive drinking norms education: A review of the research on personalised normative feedback. Journal of American College Health, 54(4) 213 - 218.

Lewis, M. L., et al. (2007). Gender-specific normative misperceptions of risky sexual behaviour and alcohol-related risky sexual behaviour. Sex Roles, 2007(57) 81 - 90.

Linkenbach, J. W. (2003). The Montana Model: Development and Overview of a Seven-Step Process for Implementing Macro-Level Social Norms Campaigns. The Social Norms Approach to Preventing School and College Age Substance Abuse: A Handbook for Educators, Counselors, and Clinicians. H. W. Perkins. San Francisco, Jossey-Bass. 
Lintonen, T. and Konu, A. (2004). The misperceived social norm of drunkenness among early adolescents in Finland. Health Education Research, 19(1) 64 - 70.

Mahler, H. I. M., et al. (2008). Social norms information enhances the efficacy of an appearance-based sun protection intervention. Social Science and Medicine, 67(321 - 329).

McAlaney, J. and McMahon, J. (2006). Establishing the rates of binge drinking in the UK: Anomalies in the data. Alcohol \& Alcoholism, 41(4) 355 - 357.

McAlaney, J. and McMahon, J. (2007). Normative beliefs, misperceptions and heavy episodic drinking in a British student sample. Journal of Studies on Alcohol and Drugs, 68(3) 385 - 392.

Moore, K. and Miles, S. (2004). Young people, dance, and the sub-cultural consumption of drugs. Addiction Research and Theory, 12507 523.

Moreira, M. T., et al. (2009). Social norms interventions to reduce alcohol misuse in University or College students, The Cochrane Collaboration. The Cochrane Library 2009 Issue 3.

Naysmith, S. (2007). Calling time on problem thinking. The Herald. Glasgow.

Neighbors, C., et al. (2006). Normative misperceptions and temporal precedence of perceived norms and drinking. Journal of Studies on Alcohol, 67290 - 299.

Neighbors, C., et al. (2004). Targeting misperceptions of descriptive drinking norms: Efficacy of a computer delivered personalised normative feedback intervention. Journal of Consulting and Clinical Psychology, 72(3) 434 - 447.

Neighbors, C., et al. (2007). Injunctive norms and problem gambling among college students. Journal of Gambling Studies, 23253 273.

Page, R. M., et al. (2008). Social normative perceptions of alcohol use and episodic heavy drinking among Central and Eastern European adolescents. Substance Use and Misuse, 43361 - 373.

Perkins, H. W. (1997). College student misperceptions of alcohol and other drug use norms among peers. Designing alcohol and other drug prevention programmes in higher education: Bringing theory into practice. H. W. Perkins. Newton, CA, The Higher Education Center for Alcohol and Other Drug Prevention: 177 - 206.

Perkins, H. W. (2002). Surveying the damage: A review of research and on consequences of alcohol misuse in college populations. Journal of Studies on Alcohol, Supplement 1491 - 100.

Perkins, H. W. (2003). The emergence and evolution of the social norms approach to substance abuse prevention. The social norms approach to preventing school and college age substance abuse: A handbook for educators, counselors and clinicians. H. W. Perkins, Jossey-Bass: 3 - 17.

Perkins, H. W. (2007a). Is everybody really doing it? Using a social norms approach successfully reduce alcohol abuse and other risk behaviours. SAADAT Annual Conference Edinburgh. 
Perkins, H. W. (2007b). Misperceptions of Peer Drinking Norms in Canada: Another Look at the 'Reign of Error' and Its Consequences among College Students. Addictive Behaviors, 322645 - 2656.

Perkins, H. W. and Berkowitz, A. D. (1986). Perceiving the community norms of alcohol use among students: Some research implications for campus alcohol education programming. International Journal of the Addictions, 21971 - 976.

Perkins, H. W. and Craig, D. W. (2003). The Hobart and William Smith Colleges experiment: A synergistic social norms approach using print, electronic medium and curriculum infusion to reduce collegiate problem drinking. The social norms approach to preventing school and college age substance abuse: A handbook for educators counselors and clinicians. H. W. Perkins. San Francisco, Jossey-Bass.

Perkins, H. W., et al. (2005). Misperceiving the college drinking norm and related problems: A nationwide study of exposure to prevention, information, perceived norms and student alcohol misuse. Journal of Studies on Alcohol, 66470 - 478.

Perkins, H. W., et al. (1999). Misperceptions of the norms for the frequency of alcohol and other drug use on college campuses. Journal of American College Health, 47253 - 258.

Perkins, H. W. and Wechsler, H. (1996). Variation in perceived college drinking norms and it's impact on alcohol abuse: A nationwide survey. Journal of Drug Issues, 26961 - 974.

Plant, M. and Plant, M. (2006). Binge Britain: Alcohol and the National Response. Oxford, Oxford University Press.

Prentice, D. A. and Miller, D. T. (1993). Pluralistic ignorance and alcohol use on campus: Some consequences of misperceiving the social norms. Journal of Personality and Social Psychology, 64243 - 256.

Roche, A. and Watt, K. (1999). Drinking and university students: from celebration to inebriation. Drug and Alcohol Review, 18(4) 389-99.

Schmidt, E., et al. (2009). Changing social norms: A mass media campaign for youth ages 12 - 18. Canadian Journal of Public Health. Revue Canadienne de Sante Publique, 100(1) 41 - 45.

Schroeder, C. M. and Prentice, D. A. (1998). Exploring pluralistic ignorance to reduce alcohol use among college students. Journal of Applied Social Psychology, 282150 - 2180.

Thombs, D. L., et al. (2004). A close look at why one social norm campaign did not reduce student drinking. Journal of American College Health, 5361 - 68.

Thombs, D. L., et al. (2005). The role of sex-specific normative beliefs in undergraduate alcohol use. American Journal of Health Behaviour, 29(4) 342 - 351

Thombs, D. L., et al. (1997). Social context, perceived norms and drinking behaviour in young people. Journal of Substance Abuse, 9257 267.

Turner, J., et al. (2008). Declining negative consequences related to alcohol misuse among students exposed to a social norms marketing intervention on a college campus. Journal of American College Health, 57(1) 85 - 93. 
Walters, S. T. (2000). In praise of feedback: an effective intervention for college students who are heavy drinkers. Journal of American College Health, 48(5) 235-238.

Wechsler, H. (2004). Colleges respond to student binge drinking: Reducing student demand or limiting access. Journal of American College Health, 52(4) 159 - 168.

Wechsler, H. and Kuo, M. (2000). College students define binge drinking and estimate it's prevalence: Results of a national survey. Journal of American College Health, 4957 - 64

Wechsler, H., et al. (2003). Perceptions and reality: A national evaluation of social norms marketing interventions to reduce college student's heavy alcohol use. Journal of Studies on Alcohol, 484 - 494.

White, H. R., et al. (2006). Evaluating two brief substance-use interventions for mandated college students. Journal of Studies on Alcohol, 67(2) 309 - 317.

Wilson, B. (2007). Perceived Norms of Alcohol and Tobacco Consumption - Pilot Studies in Scottish Educational Institutions (S3M-00668). Scottish Parliament.

Wolfson, S. (2000). Student's estimates of the prevalence of drug use: Evidence for a false consensus effect. Psychology of Addictive Behaviours, 14(3) 295 - 298. 